\title{
Mechanical Properties of Plant Fibers Reinforced Alkali-activated Slag Cementitious Material at High Temperature
}

\author{
Jing Zhu ${ }^{1,2 *}$, Wenzhong Zheng ${ }^{3}$, Lesley H. Sneed ${ }^{4}$, Ying Huang ${ }^{5}$, Chonghao $\mathrm{Xu}^{3}$ \\ ${ }^{1}$ Key Laboratory of Earthquake Engineering and Engineering Vibration, Institute of Engineering Mechanics, China Earthquake \\ Administration, Harbin 150080, China \\ ${ }^{2}$ College of Civil Engineering and Architecture, Harbin University of Science and Technology, Harbin 150080, China \\ ${ }^{3}$ Key Lab of Structures Dynamic Behavior and Control of the Ministry Education, Harbin Institute of Technology, Harbin \\ 150090, China \\ ${ }^{4}$ Department of Civil, Architectural and Environmental Engineering, Missouri University of Science and Technology, Rolla, \\ MO 65401, USA \\ ${ }^{5}$ Department of Civil Engineering, North Dakota State University, Fargo, ND 58108, USA
}

Corresponding Author Email: zhujing@hrbust.edu.cn

https://doi.org/10.18280/acsm.430408

Received: 17 April 2019

Accepted: 30 June 2019

\section{Keywords:}

Alkali-activated slag cementitious material (AASCM), ground-granulated blast-furnace slag (GGBFS), high temperature, mechanical properties, plant fiber

\begin{abstract}
With the depletion of natural resources and the growing awareness of environmental protection, it is increasingly important to apply more renewable resources in construction material. Considering the low-cost and abundance of plant fibers, this paper proposes a novel cementitious material called plant fibers reinforced alkali-activated slag cementitious material (PF-AASCM). Specifically, the author investigated the types and features of fibers and how they affect the AASCM properties. On this basis, the influencing factors of the mechanical properties and microstructure of PF-AASCM were determined, and the measures to enhance the compressive and flexural strengths of the PF-AASCM were evaluated one by one. Next, the potential of applying plant fibers as internal enhancements of the AASCM was thoroughly explored. The results show that the PF-AASCM is economically and technically viable for many construction applications. The plant fiber reinforcement can enhance the ultimate strength of the AASCM rapidly (70 \% growth in $7 \mathrm{~d}$ and $120 \mathrm{MPa} / 17,000 \mathrm{psi}$ in $28 \mathrm{~d}$ ), resulting in excellent acid resistance and freeze-thaw durability. In addition, the optimal mix ratio is 1:4 wt.\% between sodium hydroxide and potassium silicate. Under this ratio, the mechanical properties and microstructural features of the sample will be comparable to those of Portland cement. The compressive strength of single-row-hole sample of wheat straw reinforced AASCM was $10.75 \mathrm{MPa}$ at room temperature, equivalent to that of standard concrete sample MU7.5. The compressive strength of such a PF-AASCM decreased linearly with the growth in temperature. After the temperature reached $600{ }^{\circ} \mathrm{C}$, the plant fiber still exerted a certain tensile force on the matrix. By contrast, the polypropylene fiber started to melt down after the temperature increased to $200 \sim 400{ }^{\circ} \mathrm{C}$, causing brittle failure of the matrix. Under the high temperature of $200 \sim 400{ }^{\circ} \mathrm{C}$, the fine steel fiber enhanced the compressive properties of samples, which showed clear plastic deformation. The research results shed new light on reducing pollution and enhancing AASCM ductility.
\end{abstract}

\section{INTRODUCTION}

China generates 240 million tons of ground-granulated blast-furnace slag (GGBFS) annually, of which about $87 \%$ are recycled and the remaining $13 \%$ are landfilled [1]. The disposal of such a huge volume of GGBFS poses a serious environmental problem. The disposal problem can be solved partially by replacing cement with the GGBFS and other industrial by-products (e.g. fly ash and silica fume), forming an alkali-activated slag cementitious material (AASCM) [2]. In fact, the AASCM has been increasingly adopted to substitute traditional Portland cement, thanks to its positive environmental impact and consideration consumption of GGBFS.

The AASCM, containing 40 95\% Class 75 105 GGBFS, is a suitable construction material to bind alkali activators, water, and fibers into a matrix. Since it was proposed by
Purdon [3], the AASCM has been tested for tensile properties, microstructure, and most importantly, economic viability. Extensive studies have demonstrated that the AASCM exhibits similar mechanical strength to Portland cement [4], and even outperforms the latter in many aspects: early strength development, durability, resistance to chemical attack, hydration heat and resistance to freeze-thaw cycles [5]. In addition, it is now widely accepted that the AASCM has advantages over Portland cement in terms of energy cost, strength and high-temperature resistance [6].

The only undesired property of the AASCM is the high brittleness, i.e. the low tensile strength. This defect can be solved by including short discrete fibers into the matrix to control or eliminate crack initiation, propagation or coalescence [7-9]. The traditional options of such fibers include steel fiber, polypropylene fiber and glass fiber. In recent years, the traditional fibers are gradually been replaced 
with plant fibers extracted from wheat, corn, sisal, jute, cotton, etc. The plant fibers are environmentally friendly, readily available in fibrous form, and easily extracted at a low cost [10, 11]. Many scholars at home and abroad have explored plant fibers with good mechanical properties, aiming to make the materials greener and stronger [3, 12].

According to statistics, the annual straw production in China is about 700 million tons. Among then, 200 million tons are burned in the open air, which both pollutes the air and causes fire and traffic accidents [13, 14]. Actually, the burning is also a great waste of low-cost renewable resources. With light weight, large length-diameter ratio, high strength ratio and good biodegradability, the straws meet the requirements of Chinese sustainable development strategy $[15,16]$. If fibers can be extracted from the straws and included into the matrix of the AASCM, there will be a sharp decline in the energy consumption, environmental pollution and resource consumption in the building field.

In addition to tensile strength, many other engineering properties of the AASCM can be improved through fiber inclusion, namely, fracture toughness, fatigue resistance, impact, wear, thermal shock and shrinkage behavior [17-20]. The most important effect of fiber inclusion is preventing the crack propagation in the AASCM. Once included, the fibers will distribute randomly in the AASCM, bear some stress in the AASCM, and transfer some stress to stable areas, leaving no internal stress to induce microcracks [21-23]. More importantly, the reinforcement of the AASCM with plant fibers can reduce the dependence on nonrenewable energy or material, and lower pollutant emissions.

The performance of the AASCM reinforced by plant fibers (PF-AASCM) depends on the properties of the AASCM and those of the fibers [24]. In the PF-AASCM, the matrix properties directly hinge on alkali content and fiber dosage [25]. However, there are only a few reports on how fibers affect the mechanical properties of the AASCM. Wei et al. [26-27] investigated the effects of plant fiber inclusion on mechanical strength and fracture toughness of the AASCM, revealing that the inclusion can greatly improve the tensile, flexural and ductile strengths but reduce the compressive strength. Puertas et al. [28] found that the inclusion of polypropylene fiber promotes the impact resistance of the matrix by extending the wet/dry cycles, failing to enhance the mechanical behavior, elastic modulus or freeze/thaw durability of the AASCM. Gamage et al. [29] demonstrated that carbon fiber inclusion cannot strengthen the AASCM, despite the suppression of drying shrinkage. Romildo et al. [30] shows that the addition of glass fiber strands can lower the AASCM shrinkage without weakening the mechanical properties. Penteado and Thaumaturgo [31] observed that basalt fiber increased flexural and splitting tensile strengths of the AASCM.

Considering the above, this paper attempts to improve the mechanical properties of the AASCM through the inclusion of plant fibers. For this purpose, the author explored the impacts of fiber type and dosage on mechanical properties and microstructure, and then designed a high-performance matrix to replace Portland cement. With a compressive strength over $108 \mathrm{MPa}$, the proposed matrix was produced by adding $1 \%$ $2 \sim 3 \mathrm{~cm}$-long plant fibers to the GGBFS and treated with alkali activators. The utilization of the GGBFS, a waste material, in the AASCM helps reduce environmental pollution, control greenhouse gas emitted in cement production, and conserve existing natural resources. In addition, the AASCM was reinforced with plant fibers and made into samples, which feature low brittleness, reduced shrinkage and delayed fracture. The reinforcement method was proved as stable and reliable basis for the design of AASCM samples. The research results make up for the lack of standard design method for the PFAASCM, and shed new light on comprehensive use of plant fibers like rice straw, wheat straw and corn stalk.

\section{PROPORTION TEST}

\subsection{Raw materials}

\section{1) The GGBFS}

The G95 GGBFS samples were provided by Tangshan Iron and Steel Company. The chemical composition of the samples is listed in Table 1. The GGBFS is acidic in nature because of the following activity indices: the mass coefficient of 1.69 , the alkaline coefficient of $0.97<1$, and the activity coefficient of 0.42 .

Table 1. Chemical composition of the GGBFS (/\%)

\begin{tabular}{cccccccc}
\hline $\mathrm{SiO}_{2}$ & $\mathrm{Al}_{2} \mathrm{O}_{3}$ & $\mathrm{CaO}$ & $\mathrm{MgO}$ & $\mathrm{TiO}_{2}$ & $\mathrm{FeO}$ & $\mathrm{MnO}$ & $\mathrm{K}_{2} \mathrm{O}$ \\
\hline 36.9 & 15.66 & 37.57 & 9.3 & 1.1 & 0.36 & 0.5 & 0.31 \\
\hline
\end{tabular}

\section{2) Water glass}

Potassium silicate solution, a type of water glass, was purchased from Huidacheng Chemical Plant in Beichen district of Tianjin. The specific parameters of the water glass are shown in Table 2.

Table 2. Parameters of the water glass

\begin{tabular}{ccccc}
\hline \multirow{2}{*}{ Baume degree } & \multirow{2}{*}{ Density } & \multirow{2}{*}{ Modulus } & \multicolumn{2}{c}{ Mass fraction \% } \\
\cline { 3 - 5 } & & & $\mathrm{K}_{2} \mathrm{O}$ & $\mathrm{SiO}_{2}$ \\
\hline 46.3 & 1.465 & 2.76 & 15.98 & 28.15 \\
\hline
\end{tabular}

\section{3) Sodium hydroxide}

Sodium hydroxide, analytically pure, was provided by Harbin Institute of Technology Chemical Reagent Company. The quality score of the reagent is greater than $96.0 \%$.

\section{4) Plant fibers}

Three kinds of plant fibers were selected, i.e. rice straw, wheat straw and corn stalk. The straws/stalks were cut into $2 \sim 3 \mathrm{~cm}$-long segments and melted under $750 \sim 1,100{ }^{\circ} \mathrm{C}$. The morphology of plant fibers was presented in Figure 1.

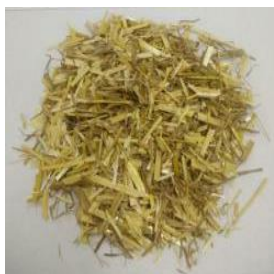

(a)Wheat Straw

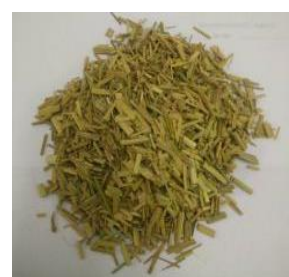

(b) Straw

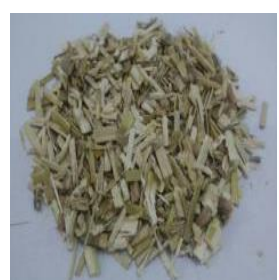

(c) Corn stalk.
Figure 1. The morphology of plant fibers

\section{5) Other fibers}

The polypropylene (PP) fiber and fine steel (XS) fiber were selected as contrastive fibers. As a bundle of monofilament fiber, the PP is $18 \sim 45 \mu \mathrm{m}$ in diameter, $12 \mathrm{~mm}$ in length, $0.91 \mathrm{~g} / \mathrm{cm}^{3}$ in density, $42 \mathrm{GPa}$ in elastic modulus, $1,600 \mathrm{MPa}$ in 
tensile strength, $5 \% \sim 12 \%$ in elongation at break, $165 \sim$ $175^{\circ} \mathrm{C}$ in melting point, and $590{ }^{\circ} \mathrm{C}$ in flash point. Produced by Anshan Changhong Steel Fiber Factory, the XS fiber used in this research is a flat steel fiber with high fineness, ultrashortness and high strength. The XS is $13 \mathrm{~mm}$ in length, $0.22 \mathrm{~m}$ in equivalent diameter and 59.1 in length-diameter ratio.

\subsection{Sample preparation and testing}

Several prismatic samples $(\mathrm{L} \times \mathrm{W} \times \mathrm{H}$ : $40 \mathrm{~mm} \times 40 \mathrm{~mm} \times 160 \mathrm{~mm}$ ) were prepared from the GGBFS, alkali activators and plant fibers for testing on flexural and compressive strengths. First, the GGBFS was mixed for about $30 \mathrm{~s}$ in a $5 \mathrm{~L}$ pan mixer. Then, the alkaline activators and water were poured into the pan, and stirred at a low speed for about 6 min until the mixture was glossy and well combined. After that, the three types of plant fibers, $1 \%$ each, were added into the mixture and stirred for about $1 \mathrm{~min}$. The fresh paste was relocated into molds of various shapes, and maintained in a humidistat at the temperature of $20 \pm 2{ }^{\circ} \mathrm{C}$ and the relative humidity of $95 \%$. The samples were demolded after $24 \mathrm{~h}$ and stored in a humidistat at the temperature of $20 \pm 2{ }^{\circ} \mathrm{C}$ and the relative humidity of $50 \%$ until testing commenced. Table 3 presents the mix ratios of different PF-AASCM samples.

With reference to "Method of testing cementsdetermination of strength (ISO method)" (GB/ t17671-1999), the compressive strength of AASCM specimens with $40 \mathrm{~mm} \times 40 \mathrm{~mm} \times 160 \mathrm{~mm}$ were tested. Firstly, $40 \mathrm{~mm} \times 40 \mathrm{~mm} \times 160 \mathrm{~mm}$ specimens were folded in half on the YAW-300 automatic folding test machine, and then the half of the post-prism specimen (the size is about $40 \mathrm{~mm} \times 40 \mathrm{~mm} \times 80 \mathrm{~mm}$ ) was broken for center pressure, the compression surface is the side of the specimen during molding. The standard compression fixture can ensure the compression surface is $40 \mathrm{~mm} \times 40 \mathrm{~mm}$. Finally, loading equipment for compression test is set with the loading rate 0.25 $\mathrm{kN} / \mathrm{s}$. By carrying the compressive and folding strength tests, the influence of factors is obtained.

Table 3. Mix ratios of different PF-AASCM samples

\begin{tabular}{ccccccc}
\hline Specimen type & Modulus & Alkali content & Water consumption & Fiber type & Mixing amount & Alkali treatment (min) \\
\hline ASZ1 & 1.0 & 14 & 32 & Z & 1 & 20 \\
ASP1 & 1.0 & 14 & 32 & PP & 1 & - \\
ASX1 & 1.0 & 14 & 32 & XS & 1 & - \\
\hline
\end{tabular}

\section{EFFECT ANALYSIS OF KEY PARAMETERS}

\subsection{Effect of the type of alkali activator}

Two types of alkali activators were adopted in our research, namely, potassium silicate solution and sodium silicate solution. Under the same conditions, the former enjoys better activation effect than the latter. Our tests show that potassium silicate solution was $4.4 \%$ lower in $3 \mathrm{~d}$ compressive strength, $3.3 \%$ higher in $7 \mathrm{~d}$ compressive strength, and $16.8 \%$ higher in $28 \mathrm{~d}$ compressive strength, than sodium silicate solution. In addition, potassium silicate solution was $20 \%, 24 \%$ and $60.4 \%$ higher, respectively in $3 \mathrm{~d}, 7 \mathrm{~d}$ and $28 \mathrm{~d}$ flexural strength, than sodium silicate solution. These results can be attributed to the following factors

First, the same amount of potassium silicate solution can provide more $\mathrm{OH}^{-}$than sodium silicate solution, creating a strong alkaline environment that favors the stimulation of the GGBFS. Second, the hydrolysis product of potassium silicate solution greatly promotes the polymerization of the GGBFS, compared with that of sodium silicate solution. Third, potassium silicate solution provides a wealth of $\mathrm{K}^{+}$, which speeds up the ionization and dissolution of polymer silicate and thus enhances the material strength.

\subsection{Effect of water glass modulus}

Two water glass moduli were tested in our experiments, namely, 1.0 and 2.0. Under the same conditions, the mechanical properties of the samples were better under the modulus of 1.0 than under that of 2.0. When the modulus of water glass was 1.0 , the $28 \mathrm{~d}$ compressive and flexural strengths of the samples reached $120.1 \mathrm{MPa}$ and $19.3 \mathrm{MPa}$, respectively, the initial and final coagulations took place at $16 \mathrm{~min}$ and $22 \mathrm{~min}$, respectively, and the flow degree fell between $132 \mathrm{~mm}$ and $148 \mathrm{~mm}$. When the modulus of water glass was 2.0 , the $28 \mathrm{~d}$ compressive and flexural strengths of the samples reached 109.0MPa and 16.7MPa, respectively, and the initial and final coagulations took place at $25 \mathrm{~min}$ and $34 \mathrm{~min}$, respectively. In terms of flexural strength, the $3 \mathrm{~d}, 7 \mathrm{~d}$ and $28 \mathrm{~d}$ samples with modulus $\mathrm{M}=1.0$ were $24.2 \%, 14.6 \%$ and $15.9 \%$ higher, respectively, than those with modulus $\mathrm{M}=2.0$. In terms of compressive strength, the $3 \mathrm{~d}, 7 \mathrm{~d}$ and $28 \mathrm{~d}$ samples with modulus $\mathrm{M}=1.0$ were $10.1 \%, 27.1 \%$ and $22.9 \%$ higher, respectively, than those with modulus $\mathrm{M}=2.0$.

For the sample of potassium silicate solution with modulus $\mathrm{M}=1.0$, the compressive and flexural strengths of the AASCM at $28 \mathrm{~d}$ were $31.7 \%$ and $15.5 \%$ higher than that of AASCM at $7 \mathrm{~d}$, respectively. The results show that the AASCM is a high-performance material with fast hardening and early strength. Therefore, the modulus of potassium silicate solution was determined as 1.0 .

\subsection{Effect of alkali content}

The alkali contents of $8 \%, 10 \%, 12 \%$ and $14 \%$ were tested under the same GGBFS quality and moduli of potassium silicate solution. The test results show that the compressive and flexural strengths of the samples increased with the alkali content. The compressive and flexural strengths peaked at 93.4MPa and 14.5 MPa, respectively, under the alkali content of $14 \%$. The peak compressive strength was respectively $33.7 \%, 14.4 \%$ and $11.9 \%$ higher than that under the alkali contents of $8 \%, 10 \%$ and $12 \%$, while the peak flexural strength was respectively $33.8 \%, 25.8 \%$ and $20.3 \%$ higher than that under the alkali contents of $8 \%, 10 \%$ and $12 \%$.

\subsection{Effect of water content}

Five different water contents of the AASCM were tested in our experiment: $28 \%, 32 \%, 35 \%, 38 \%$ and $42 \%$. Under the same conditions, the samples exhibited better mechanical properties under the water contents of $32 \%$ and $35 \%$. Under the water content of $38 \%$, the compressive and flexural 
strengths of the samples were 96.3 $\mathrm{MPa}$ and 6.2 $\mathrm{MPa}$, respectively; under the water content of $42 \%$, the compressive and flexural strengths of the samples were 106.5 $\mathrm{MPa}$ and 13.4MPa, respectively.

When the water content was $32 \%$, the initial and final setting times of the samples were $15 \mathrm{~min}$ and $20 \mathrm{~min}$, respectively. When the water content was $35 \%$, the initial and final setting times of the samples were $16 \mathrm{~min}$ and $22 \mathrm{~min}$, respectively. In the latter case, the flow degree fell between 125 and $140 \mathrm{~mm}$.

In view of the above results, the optimal parameters were determined as the water glass modulus of 1.0, the alkali content of $14 \%$ and the AASCM water content of $32 \%$ as block matrix. To satisfy the engineering requirements, the optimal values were adjusted under high flow degree as: the water glass modulus of 1.0 , the alkali content of $12 \%$ and the AASCM water content of $35 \%$ as masonry slurry.

\subsection{Effect of the type of plant fibers}

Three types of plant fibers were tested in our experiment, including rice straw, wheat straw and corn stalk. The experimental results show that, under the same conditions, the samples containing wheat straw achieved higher compressive and flexural strengths (108.3 $\mathrm{MPa}$ and $12.4 \mathrm{MPa})$ than those containing rice straw $(81.6 \mathrm{MPa}, 7.8 \mathrm{MPa})$ or corn stalk (108.1 MPa, 9.6 MPa). The relative advantage of wheat straw can be explained as follows.

The straws, especially wheat straw, are soft enough to distribute evenly in the samples, while the corn stalk is too hard and bulky to float on the matrix surface, leading to an uneven distribution. As a result, the samples containing corn stalk showed the poorest mechanical performance.

Our experiments indicate that the AASCM samples were flaky and fissured at the same time. Before the addition of plant fibers, the samples gave off a loud noise in the antiflexural test, a signal of brittle facture. By contrast, the samples containing each type of plant fiber only cracked slightly. It can be seen that plant fibers mitigated the brittle fracture of the matrix, delayed crack propagation and enhanced AASCM ductility.

\subsection{Effect of fiber treatment method}

To control the water content in plant fibers and enhance the interfacial bonding, the rice straw and the wheat straw were processed by two kinds of alkali treatments, or treated by two types of acid treatments. The two kinds of alkali treatments only differ in treatment duration ( $20 \mathrm{~min}$ vs. $60 \mathrm{~min}$ ), but share the same steps: soaking the plant fibers in sodium hydroxide solution (mass fraction: $10 \%$ ) and then in water for $2 \mathrm{~min}$. The two types of acid treatments use different acids (sulfuric acid and hydrochloric acid) but follow the same procedure: soaking the plant fibers in $10 \%$ acid solution for $20 \mathrm{~min}$, then in $10 \%$ sodium hydroxide solution for $20 \mathrm{~min}$, and finally in water for $2 \mathrm{~min}$.

The experimental results show that the water content of plant fibers was controlled at $15 \%$. No major difference in mechanical properties was observed between the samples after $20 \mathrm{~min}$-long alkali treatment and those after $60 \mathrm{~min}$-long alkali treatment. The $3 \mathrm{~d}$ compressive and flexural strengths of all samples were presented in Figure 2 below. It is clear that the acid treated wheat straw boasted slightly better mechanical properties than acid treated wheat straw and untreated wheat straw.

The $28 \mathrm{~d}$ compressive and flexural strengths of treated wheat straw with alkali samples were 108.3 $\mathrm{MPa}$ and 12.4 MPa, respectively. Those of treated wheat straw with acid samples were $104.5 \mathrm{MPa}$ and $11.3 \mathrm{MPa}$, respectively. Those of untreated samples were 92.6 MPa and $10.1 \mathrm{MPa}$, respectively. The comparison shows that the wheat straw outperformed the rice straw, and the best enhancement effect belonged to the wheat straw treated by alkali for $20 \mathrm{~min}$. The AASCM sample reinforced by wheat straw in a single row of holes (single-rowhole) could reach the compressive strength of $10.75 \mathrm{MPa}$ at room temperature, which is equivalent to the compressive strength of standard concrete sample MU7.5. The failure mode of the AASCM sample thus reinforced is displayed in Figure 2 below.

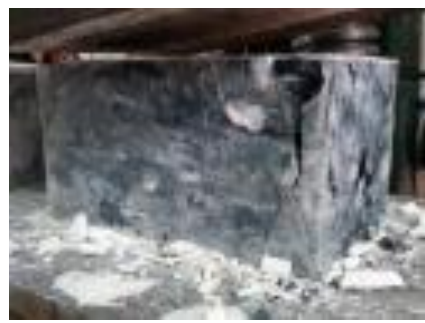

(a) AASCM matrix block

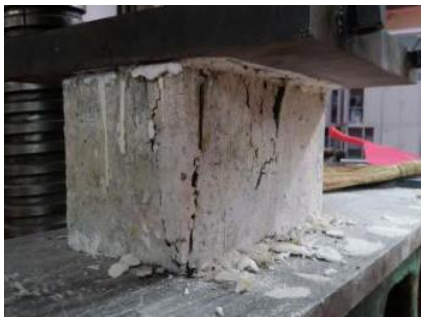

(b) Wheat straw reinforced AASCM block

Figure 2. Failure mode of the single-row-hole strawreinforced AASCM

\section{MICROANALYSIS OF PF-AASCM}

The AASCM samples reinforced separately by rice straw, wheat straw and corn stalk were subjected to scanning electron microscopy (SEM). The analysis results are displayed in Figure 3. As shown in the figure, the surface of wheat straw was serrated and closely interlocked with the matrix, while the surfaces of rice straw and corn stalk were too smooth to bind to the matrix easily. Thus, the microstructure difference determines the macro mechanical properties, which further verifies the toughening effect of the wheat straw.

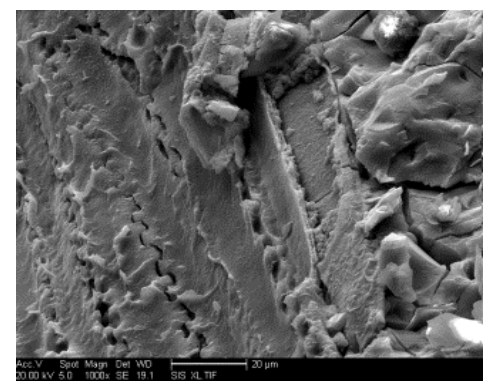

(a) wheat straw 


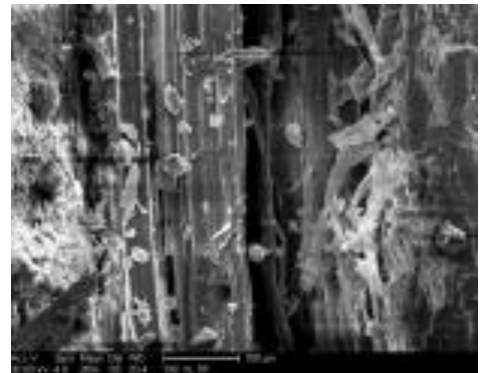

(b) straw

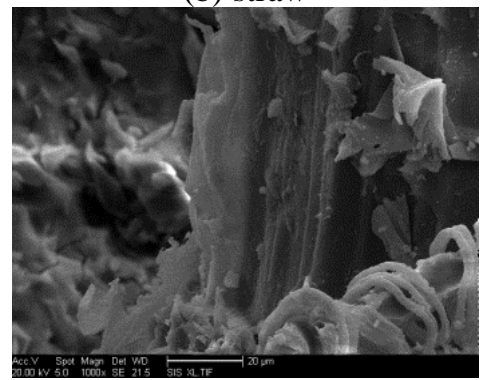

(c) corn stalk

Figure 3. Microstructure of plant fibers reinforced AASCM samples

\section{MECHANICAL PROPERTIES OF AASCM REINFORCED BY DIFFERENT FIBERS UNDER HIGH TEMPERATURE}

The compressive strength-temperature relationships of the AASCM samples reinforced by different fibers in different patterns are presented in Figure 4. Plant fiber can effectively prevent the brittle failure of AASCM matrix under high temperature. Despite the high temperature of $600{ }^{\circ} \mathrm{C}$, the matrix still had a good tensile resistance. The high-temperature compressive strength of ASZ1 linearly decreased with the increase in temperature. After the temperature reached $600{ }^{\circ} \mathrm{C}$, the plant fiber still exerted a certain tensile force on the matrix.

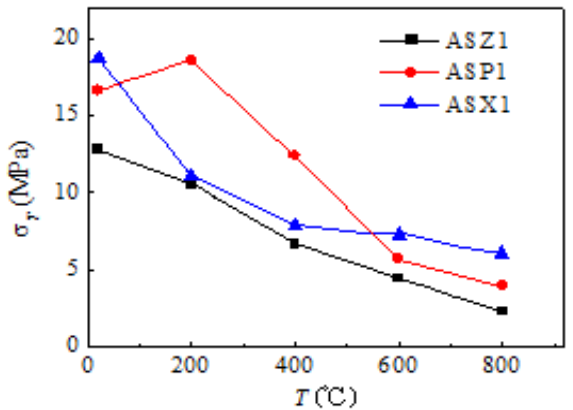

(a) Single-row-hole block

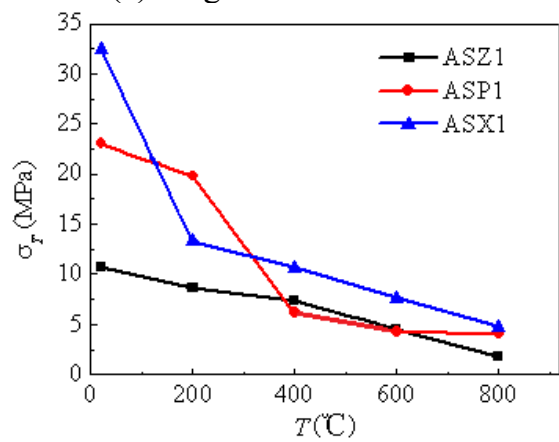

(b)Single-hole block

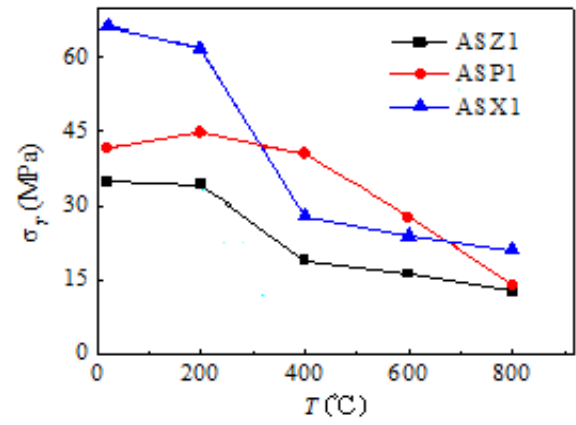

(c) Solid brick

Figure 4. Compressive strengths of AASCM samples reinforced by different fibers at different temperatures

For the PP-reinforced AASCM sample as shown in Figure 4 , the PP gradually melted in the multiple holes after the temperature increased to $200 \sim 400{ }^{\circ} \mathrm{C}$, which has an adverse effect on the compressive strength. Then, the sample strength decreased deeply, leading to a sudden brittle failure. The compressive failure features are similar to those of the AASCM matrix. After the temperature increased to $400 \sim 800{ }^{\circ} \mathrm{C}$, the sample basically lost its strength. Fortunately, under the high temperature of $200 \sim 400{ }^{\circ} \mathrm{C}$, the compressive strength of XS-reinforced AASCM sample plunged under the high temperature of $200 \sim 400{ }^{\circ} \mathrm{C}$ [32]. The XS managed to enhance the compressive and flexural strengths of the sample. When the ASX1 samples were damaged, the deformation was clearly plastic. By contrast, with the increase in temperature, almost all AASCM samples reinforced by different fibers dropped to different degrees. The only exception is the PPreinforced AASCM single-hole sample, whose compressive strength slightly increased under the high temperature of $200{ }^{\circ} \mathrm{C}$. The trend is similar to that of solid sample.

Through regression analysis, the author established the formulas to compute the compressive strength of the PFAASCM samples under different temperatures. The relationship between compressive strength and temperature can be expressed as:

Single-row-hole sample:

$$
\frac{\sigma_{T}}{\sigma}=1.021-1.069\left(\frac{T}{1000}\right) \quad 20^{\circ} \mathrm{C} \leq T \leq 800^{\circ} \mathrm{C}, R^{2}=0.916
$$

Single-hole sample:

$$
\frac{\sigma_{T}}{\sigma}=1.212-1.250\left(\frac{T}{1000}\right) \quad 20^{\circ} \mathrm{C} \leq T \leq 800^{\circ} \mathrm{C}, R^{2}=0.805
$$

Solid sample:

$$
\frac{\sigma_{T}}{\sigma}= \begin{cases}1.001-0.075\left(\frac{T}{1000}\right) & 20^{\circ} \mathrm{C} \leq T \leq 200^{\circ} \mathrm{C}, R^{2}=0.951 \\ 1.429-2.212\left(\frac{T}{1000}\right) & 200^{\circ} \mathrm{C}<T \leq 400^{\circ} \mathrm{C}, R^{2}=0.939 \\ 0.725-0.453\left(\frac{T}{1000}\right) & 400^{\circ} \mathrm{C}<T \leq 800^{\circ} \mathrm{C}, R^{2}=0.923\end{cases}
$$

where, $\sigma_{\mathrm{T}}$ is the compressive strength of AASCM samples reinforced by different fibers at a certain temperature (MPa); 
$\sigma$ is the compressive strength of AASCM samples reinforced by different fibers at room temperature $(\mathrm{MPa}) ; \mathrm{T}$ is temperature, ranging from $20{ }^{\circ} \mathrm{C}$ to $800{ }^{\circ} \mathrm{C} ; \mathrm{R}^{2}$ is the correlation coefficient on fitting accuracy.

\section{CONCLUSIONS}

(1) The straws are more effective than corn stalk in the enhancement of the AASCM. Meanwhile, the corn stalk exhibits the poorest performance, because it is too hard and bulk to integrate into the matrix. Comparatively, the wheat straw has better enhancing effect than the rice straw. In general, it can be concluded that PF-AASCM is a good way to recycle waste and protect the environment.

(2) Plant fibers are suitable for reuse due to their wide availability and low cost. The PF-AASCM offers an important way to recycle these renewable resources. The plant fiber reinforcement can enhance the ultimate strength of the AASCM rapidly ( $70 \%$ growth in $7 \mathrm{~d}$ and $120 \mathrm{MPa} / 17,000$ psi in 28d), resulting in excellent acid resistance and freeze-thaw durability. In addition, the optimal mix ratio is 1:4 wt.\% between sodium hydroxide and potassium silicate. Under this ratio, the mechanical properties and microstructural features of the sample will be comparable to those of Portland cement.

(3) The compressive strength of single-row-hole sample of wheat straw reinforced AASCM was $10.75 \mathrm{MPa}$ at room temperature, equivalent to that of standard concrete sample MU7.5. The novel PF-AASCM samples have many advantages, such as high strength, low cost and hightemperature resistance. After the temperature reached $600^{\circ} \mathrm{C}$, the plant fiber still exerted a certain tensile force on the matrix. By contrast, the PP started to melt down after the temperature increased to $200 \sim 400^{\circ} \mathrm{C}$, causing brittle failure of the matrix. Under the high temperature of $200 \sim 400^{\circ} \mathrm{C}$, the XS enhanced the compressive properties of samples, which showed clear plastic deformation. The research results shed new light on reducing pollution and enhancing AASCM ductility.

\section{ACKNOWLEDGMENT}

This work was financially supported by the National Natural Science Foundation of China (NO. 51508140) and the Natural Science Foundation of Heilongjiang (NO LH2019E066).

\section{REFERENCES}

[1] Zheng, W.Z., Zhu, J. (2015). Application foundation of alkali-activated slag cementitious material in structural engineering. Harbin Institute of Technology Press, 1-19. ISBN/ISSN: 978-7-5603-5022-6

[2] Won, J.P., Kang, H.B., Lee, S.J., Kang, J.W. (2012). Eco-friendly fireproof high-strength polymer cementitious composites. Construction and Building Materials, 30: 406-412. https://doi.org/10.1016/j.conbuildmat.2011.12.034

[3] Sood, M., Dwivedi, G. (2018). Effect of fiber treatment on flexural properties of natural fiber reinforced composites: A review. Egyptian Journal of Petroleum, 27(4):

$775-783$

https://doi.org/10.1016/j.ejpe.2017.11.005
[4] Ding, Y., Dai, J.G., Shi, C.J. (2016). Mechanical properties of alkali-activated concrete: A state-of-the-art review. Construction and Building Materials, 127(30): 68-79.

https://doi.org/10.1016/j.conbuildmat.2016.09.121

[5] Shi, C., Roy, D., Krivenko, P. (2006). Alkali-Activated Cements and Concretes. CRC Press, 4-17. https://doi.org/10.4324/9780203390672

[6] Puertas, F., Amat, T., Fernandez-Jimenez, A., Vazquez, T. (2003). Mechanical and durable behaviour of alkalin cement mortars reinforced with polypropylene fibers. Cement and Concrete Research, 33(12): 2031-2036. https://doi.org/10.1016/S0008-8846(03)00222-9

[7] Pickering, K.L., Aruan Efendy, M.G., Le, T.M. (2016). A review of recent developments in natural fibre composites and their mechanical performance. Composites: Part A: Applied Science and Manufacturing, 83: 98-112. https://doi.org/10.1016/j.compositesa.2015.08.038

[8] Sahmaran, M., Yaman, I.Ö. (2007). Hybrid fiber reinforced self-compacting concrete with a high-volume coarse fly ash. Construction and Building Materials, 21(1):

$150-156$. https://doi.org/10.1016/j.conbuildmat.2005.06.032

[9] Aydin, S., Baradan, B. (2013). The effect of fiber properties on high performance alkali-activated slag/silica fume mortars. Composites: Part B, 45(1): 6369. https://doi.org/10.1016/j.compositesb.2012.09.080

[10] Melchert, L. (2007). The Dutch sustainable building policy: A model for developing countries? Building and Environment, 42(2): 893-901. https://doi.org/10.1016/j.buildenv.2005.10.007

[11] Onuaguluchi, O., Banthia, N. (2016). Plant-based natural fibre reinforced cement composites: A review. Cement and Concrete Composites, 68: 96-108. https://doi.org/10.1016/j.cemconcomp.2016.02.014

[12] Zhu, J., Zheng, W.Z. (2012). Shear performance of alkali-activated slag cementitious material used for FRPstrengthened concrete structures. Journal of Southeast University (Natural Science Edition), 42(5): 962-969. https://doi.org/10.1088/1757-899X/281/1/012005

[13] Zhu, J., Zhe, W.Z., Xie, L.L., Wu, Y.Q., Zhang, Y.X., Fu, J.X. (2018). Study on the performance of reinforced concrete blocks treated by styrene- acrylic emulsion. Chemical Engineering Transactions, 66: 85-90. https://doi.org/10.3303/CET1866015

[14] Palomo, A., Alonso, S., Fernandez-Jimenez, A. (2008). Alkaline activation of fly ashes, NMR study of the reaction products, Journal of the Amerian Ceramic Society, $87(6)$ : 1141-1145. https://doi.org/10.1111/j.1551-2916.2004.01141.x

[15] Zheng, W.Z., Zhu, J. (2013). The effect of elevated temperature on bond performance of alkali-activated GGBFS paste. Journal of Wuhan University of Technology (Materials Science Edition), 28(4): 721-725. https://doi.org/10.1007/s11595-013-0759-5

[16] Cardinale, T., Sposato, C., Feo, A.P., Fazio, D. (2018). Clay and fibers: Energy efficiency in buildings between tradition and innovation. Mathematical Modelling of Engineering Problems, 5(3): 183-189. https://doi.org/10.18280/mmep.050308

[17] Al-Otaibi, S. (2008). Durability of concrete incorporating GGBS activated by water-glass. Construction and Building Materials, 22(10): 2059-2067. 
https://doi.org/10.1016/j.conbuildmat.2007.07.023

[18] Sofi, M., Van Deventer, J.S.J., Mendis, P.A., Lukey, G.C. (2007). Engineering properties of inorganic polymer concretes (IPCs). Cement and Concrete Research, 37(2): 250-257. https://doi.org/10.1016/j.cemconres.2006.10.008

[19] Oh, R.O., Cha, S.S., Park, S.Y., Lee, H.J., Park, S.W., Park, C.G. (2014). Mechanical properties and water puri fication characteristics of natural jute fiber-reinforced non-cement alkali-activated porous vegetation blocks. Paddy and Water Environment, 12(S1): 149-156. https://doi.org/10.1007/s10333-014-0433-3

[20] Atis, C.D., Bilim, C., Celik, Ö., Karahan, O. (2009). Influence of activator on the strength and drying shrinkage of alkali-activated slag mortar. Construction and Building Materials, 23(1): 548-555. https://doi.org/10.1016/j.conbuildmat.2007.10.011

[21] Ismail, I., Bernal, S.A., Provis, J.L., Hamdan, S., Van Deventer, J.S.J. (2013). Microstructural changes in alkali activated fly ash/slag geopolymers with sulfate exposure. Materials and Structures, 46(3): 361-373. https://doi.org/10.1617/s11527-012-9906-2

[22] Shi, C.J., Roy, D., Krivenko, P. (2006). Alkali-activated cements and concretes. New York: Taylor and Francis, 10-47. https://doi.org/10.4324/9780203390672

[23] Van Jaarsveld, J.G.S., Van Deventer, J. (1999). The potential use of geopolymeric materials to immobolise toxic metals: Part II. Materials and leaching characteristics, Minerals Engineering, 10(12): 659-669. https://doi.org/10.1016/S0892-6875(98)00121-6

[24] Banthia, N., Sheng, J. (1996). Fracture toughness of micro-fiber reinforced cement composites. Cement and Concrete Composites, 18(4): 251-269. https://doi.org/10.1016/0958-9465(95)00030-5

[25] Silva, F.D.A., Chawla, N., Filho, R.D.D.T. (2008). Tensile behavior of high performance natural (sisal) fibers. Composites. Science and Technology, 68(15-16): 3438-3443.

https://doi.org/10.1016/j.compscitech.2008.10.001

[26] Wei, J.Q., Meyer, C. (2017). Degradation of natural fiber in ternary blended cement composites containing metakaolin and montmorillonite. Corrosion Science, 120(15): 42-60. https://doi.org/10.1016/j.corsci.2016.12.004

[27] Wei, J.Q., Maa, S.W., Thomas, D.G. (2016). Correlation between hydration of cement and durability of natural fiber-reinforced cement composites. Corrosion Science, 106: 1-15. https://doi.org/10.1016/j.corsci.2016.01.020

[28] Puertas, F., Amat, T., Fernandez-Jimenez, A., Vazquez, T. (2003). Mechanical and durable behaviour of alkalin cement mortars reinforced with polypropylene fibers. Cement and Concrete Research, 33(12): 2031-2036. https://doi.org/10.1016/S0008-8846(03)00222-9

[29] Gamage, J.C.P.H., Al-Mahaidi, R., Wong, M.B. (2006). Bond characteristics of CFRP plated concrete members under elevated temperatures. Composite Structures, 75(1-4): 199-205. https://doi.org/10.1016/j.compstruct.2006.04.068

[30] Romildo, D., Toledo, F., Karen, S. (2003). Development of vegetable fibre-mortar composites of improved durability. Cement \& Concrete composites, 25(2): 185196. https://doi.org/10.1016/S0958-9465(02)00018-5

[31] Penteado, D., Thaumaturgo, C. (2005). Fracture toughness of geopolymeric concretes reinforced with basalt fibers. Cement and Concrete Composites, 27(1): 49-54. https://doi.org/10.1016/j.cemconcomp.2004.02.044

[32] Wang, Y., Huang, D.K. (2017). Effect of heat treatment temperature on the structure and tribological properties of nanometer lanthanum borate. International Journal of Heat and Technology, 35(1): 53-58. https://doi.org/10.18280/ijht.350107 